\title{
Persistence of somatostatinergic tone in acromegaly
}

\author{
Roberto Attanasio, Renato Cozzi, Giuseppe Oppizzi, Daniela Dallabonzana, Iacopo Chiodini, Zaira Benini, \\ Paola Orlandi, Antonio Liuzzi and Pier Giorgio Chiodini*
}

Division of Endocrinology, Ospedale Niguarda, Milano, Italy

\begin{abstract}
Attanasio R, Cozzi R, Oppizzi G, Dallabonzana D, Chiodini I, Benini Z, Orlandi P, Liuzzi A, Chiodini PG. Persistence of somatostatinergic tone in acromegaly. Eur J Endocrinol 1995;132:27-31. ISSN 08044643

It is a matter of debate whether hypothalamic somatostatin (SRIH) secretion in acromegaly is preserved and still regulated by the physiological feedback mechanisms of growth hormone $(\mathrm{GH})$ and insulin-like growth factor I. To gather further information on this, the reproducibility of plasma GH changes induced by growth hormone-releasing hormone (GHRH) administration was evaluated in 15 acromegalic patients. There was a highly significant correlation between the peak/basal ratio $(\mathrm{P} / \mathrm{B})$ GH response in the 15 patients administered GHRH on two separate occasions $(r=0.99, p<0.001)$. The test was performed also before and after the administration of drugs able to inhibit or stimulate hypothalamic SRIH release, by activating (pyridostigmine) or inhibiting (pirenzepine) cholinergic pathways, respectively. The $G H R H$-induced $G H$ response $(P / B=2$, range $1.1-26.1)$ was increased significantly by pyridostigmine pretreatment in 30 patients $(P / B=2.6$, range $1.3-34.8 ; \mathrm{p}=0.0045)$. In nine out of 30 patients an increase of greater than $2 \mathrm{SD}$ of within-subject GHRH variability was observed in response to GHRH plus pyridostigmine when compared to GHRH alone. An inverse correlation $(r=-0.37, p<0.05)$ was observed between $\mathrm{GH}$ response to GHRH alone and after pyridostigmine pretreatment. On the contrary, no change of $\mathrm{GHRH}$-induced $\mathrm{GH}$ response was observed in 12 patients after pirenzepine pretreatment $(\mathrm{P} / \mathrm{B}=1.9$, range $1.1-5$ and $\mathrm{P} / \mathrm{B}=2$, range 1.3-6 without and after pirenzepine pretreatment, respectively). These data suggest that in acromegaly the somatostatinergic tone does not seem to fluctuate, and that it can be inhibited often by cholinergic pathway activation but not increased further by cholinergic suppression.
\end{abstract}

Roberto Attanasio, Divisione di Endocrinologia, Ospedale Niguarda, Piazza Ospedale Maggiore 3, I-20162 Milano. Italy

The GHRH-induced GH response has been shown to be variable among acromegalic patients $(1,2)$, but we are not aware of any studies on the intrasubject reproducibility of this response. As the wide intrasubject variability observed in GHRH-induced GH levels in normal subjects has been attributed to the fluctuations of hypothalamic somatostatin (SRIH) tone (3), gathering data on this matter could, in fact, indirectly shed some light on the somatostatinergic tone in acromegaly, which is still a matter of debate.

A reduction of hypothalamic SRIH secretion was suggested as being the primary cause of acromegaly (4). Recently, attention has focused on primary pituitary pathogenesis of this disease, the hypothesis being that an excess of hypothalamic SRIH occurs provided that the short-loop feedback between GH and SRIH secretion (5) is well functioning. There is, indeed, evidence that hypothalamic control of GH secretion may be preserved in acromegalic patients, because their $\mathrm{GH}$ levels often increase after stimuli such as arginine, insulin and exercise, which modulate GHRH and/or SRIH release at the hypothalamic level (6).

\footnotetext{
*Deceased.
}

To obtain information on somatostatinergic tone in acromegaly, we studied the reproducibility of the GH response to GHRH in acromegalic patients. Somatostatinergic tone also was evaluated indirectly in a larger group of patients after pharmacological manipulations: GHRH-induced GH secretion was studied after the administration of pyridostigmine (Pyr), putatively inhibiting SRIH secretion by activation of cholinergic pathways (7), and pirenzepine $(\mathrm{Pz})$, an antimuscarinic drug that is supposed to stimulate SRIH secretion (8).

\section{Materials and methods}

\section{Patients}

Thirty patients (11 males and 19 females, aged 2276 years, median 51 ) with active acromegaly (according to increased GH, not suppressible by glucose load, and high IGF-I levels) entered the study. Individual demographic and clinical data are reported in Table 1 . No patient was hyperprolactinemic. Any drug treatment aimed at lowering $\mathrm{GH}$ hypersecretion or potentially capable of interfering with GH secretion was withdrawn at least 4 weeks before the start of the study, as part of 
Table 1. Demographic and clinical data.

\begin{tabular}{|c|c|c|c|c|c|c|c|}
\hline \multirow[b]{2}{*}{$\begin{array}{l}\text { Case } \\
\text { no. }\end{array}$} & \multirow[b]{2}{*}{ Sex } & \multirow[b]{2}{*}{$\begin{array}{c}\text { Age } \\
\text { (years) }\end{array}$} & \multirow[b]{2}{*}{ Radiology $^{a}$} & \multicolumn{2}{|c|}{ Previous treatment } & \multirow[b]{2}{*}{$\begin{array}{c}\text { Replacement } \\
\text { therapy }\end{array}$} & \multirow[b]{2}{*}{$\begin{array}{l}\text { IGF-I } \\
(\mu \mathrm{g} / \mathrm{l})\end{array}$} \\
\hline & & & & Neurosurgery $^{b}$ & $\begin{array}{c}\text { Radiotherapy } \\
\text { (year) }\end{array}$ & & \\
\hline 1 & $\mathbf{M}$ & 69 & $\mathbf{M}-$ & - & - & - & 600 \\
\hline 2 & $\mathrm{~F}$ & 69 & $\mathrm{E}-$ & - & - & - & 495 \\
\hline 3 & F & 62 & $\mathrm{E}-$ & - & 1982 & - & 760 \\
\hline 4 & M & 65 & $\mathrm{~N}-$ & - & 1991 & A & 520 \\
\hline 5 & $\mathrm{~F}$ & 39 & $\mathbf{M}+$ & TNS & - & - & 756 \\
\hline 6 & $\mathrm{~F}$ & 56 & $\mathbf{M}-$ & - & - & - & 607 \\
\hline 7 & $\mathrm{~F}$ & 76 & $M+$ & - & 1976 & - & 675 \\
\hline 8 & $\mathrm{~F}$ & 54 & $M+$ & TNS & 1990 & AT & 510 \\
\hline 9 & $\mathrm{~F}$ & 44 & $M+$ & TNS, TC & 1984 & ATG & 807 \\
\hline 10 & $\mathrm{~F}$ & 44 & $\mathbf{M}+$ & $\mathrm{TC}$ & 1990 & $\mathrm{AT}$ & 616 \\
\hline 11 & $\mathbf{M}$ & 36 & $\mu-$ & TNS & 1986 & - & 540 \\
\hline 12 & $\mathrm{~F}$ & 37 & $\mathbf{M}+$ & - & - & - & 540 \\
\hline 13 & $\mathrm{M}$ & 22 & $M+$ & TNS & 1990 & $\mathrm{AG}$ & 843 \\
\hline 14 & $\mathrm{~F}$ & 56 & $\mathrm{M}-$ & TNS & 1990 & - & 602 \\
\hline 15 & $\mathrm{M}$ & 65 & $M+$ & - & 1976 & - & 700 \\
\hline 16 & $\mathbf{F}$ & 60 & $\mathrm{E}-$ & - & - & - & 652 \\
\hline 17 & $\mathrm{M}$ & 59 & $\mathrm{M}+$ & TNS & 1984 & $\mathrm{AG}$ & 525 \\
\hline 18 & $\mathbf{F}$ & 70 & $\mathrm{E}-$ & - & - & - & 945 \\
\hline 19 & $\mathrm{~F}$ & 68 & $\mathrm{M}+$ & - & - & - & 540 \\
\hline 20 & $\mathrm{~F}$ & 31 & $\mathrm{M}+$ & TNS & - & A & 562 \\
\hline 21 & $\mathrm{~F}$ & 68 & $\mathrm{M}-$ & - & - & - & 495 \\
\hline 22 & $\mathrm{M}$ & 46 & $M+$ & TNS & 1990 & $G$ & 1494 \\
\hline 23 & $\mathrm{~F}$ & 66 & $\mu-$ & - & - & - & 816 \\
\hline 24 & $\mathrm{~F}$ & 51 & $\bar{M}+$ & - & - & - & 610 \\
\hline 25 & $\mathrm{M}$ & 50 & $\mathbf{M}-$ & TNS & - & - & 690 \\
\hline 26 & $\mathrm{~F}$ & 52 & $\mu-$ & - & - & - & 610 \\
\hline 27 & $\mathrm{M}$ & 35 & $\mathbf{M}-$ & - & - & A & 540 \\
\hline 28 & $\mathrm{M}$ & 40 & $\mathrm{M}+$ & - & - & - & 1071 \\
\hline 29 & $\mathrm{M}$ & 45 & $\mathbf{M}+$ & - & - & - & 610 \\
\hline 30 & $\mathrm{~F}$ & 43 & $\mu-$ & - & - & - & 715 \\
\hline
\end{tabular}

${ }^{\text {a }} \mathrm{N}$ : normal; M: macroadenoma; $\mu$ : microadenoma; E: empty sella; '+' and '-' indicate the presence or not of suprasellar extension, respectively,

TNS: trans-sphenoidal; TC: trans-cranial.

${ }^{c}$ A: hydrocortisone; T: L-thyroxine; G: gonadal steroids.

periodic off-treatment evaluation of disease. Each patient gave informed consent after full explanation of the purpose of the study and the procedures followed were in accordance with the Helsinki Declaration of 1975 as revised in 1983.

\section{Protocol}

Fifteen patients (cases 1-13, 15, 22) underwent the GHRH (1-44) test (UCB, Bruxelles; $100 \mu \mathrm{g}$ iv at time 0) twice on different days (at least 2 days apart, range 2 days-21 months). No patient was submitted to major procedures (neurosurgery or radiotherapy) between the two tests.

All 30 patients randomly underwent tests with GHRH alone and after pretreatment with Pyr $(120 \mathrm{mg}$ administered po $60 \mathrm{~min}$ before GHRH injection), each test being separated by at least 7 days. In 12 of these patients (cases 1-12) the GHRH test was repeated after pretreatment with $\mathrm{Pz}(50 \mathrm{mg}$ administered po $120 \mathrm{~min}$ before GHRH injection). In our preliminary study these doses of $\mathrm{Pyr}$ and $\mathrm{Pz}$ were effective in increasing or lowering, respectively, plasma GH response to GHRH in normal subjects, without major side effects. At $08.00 \mathrm{~h}$ after an overnight fast and rest, while the patients were supine and awake, an indwelling needle was inserted in an antecubital vein and kept patent by slow saline infusion. After two basal samples $(-30 \mathrm{~min}, 0 \mathrm{~min})$, GHRH was injected and blood samples were collected after 15, 30, 45, 60, 90 and 120 min. When Pyr or Pz were given, two basal plasma samples were collected at -30 and $0 \mathrm{~min}$ before drug administration and thereafter every $30 \mathrm{~min}$ until GHRH injection. Blood samples collected at 15 -min intervals over a period of $120 \mathrm{~min}$ during saline infusion on another day were used as control.

In each blood sample, GH, PRL and TSH values were assayed.

All patients had previously undergone acute tests with TRH $(200 \mu \mathrm{g} \mathrm{iv})$, bromocriptine $(2.5 \mathrm{mg} \mathrm{po})$ and octreotide $(100 \mu \mathrm{g} \mathrm{sc})$, with methods described previously (3). 


\section{Methods}

Growth hormone, PRL, TSH and IGF-I were assayed in duplicate by immunoenzymatic assay, kinetic enzyme immunometric assay, solid phase two-site fluoroimmunometric assay and RIA after acid-ethanol extraction, respectively. Plasma hormone concentrations were determined in each patient in a single run. Reagents were provided by Sorin (Saluggia, Italy) for GH, DPC (Los Angeles, CA, USA) for PRL, Wallac-Oy (Turku, Finland) for TSH and Nichols Institute (San Juan Capistrano, CA, USA) for IGF-I. Standards were calibrated against first IS $80 / 505(1 \mathrm{ng}=2 \mu \mathrm{IU})$ for GH, WHO first IRP $75 / 504$ for PRL, WHO second IRP $80 / 558$ for TSH and WHO IRP $87 / 518$ for IGF-I. Normal values for adult patients in our laboratory are less than $5 \mu \mathrm{g} / \mathrm{l}$ for $\mathrm{GH}$, less than $18 \mu \mathrm{g} / \mathrm{l}$ for PRL, $0.1-$ $3.5 \mathrm{mU} / \mathrm{l}$ for TSH and $123-463 \mu \mathrm{g} / \mathrm{l}$ for IGF-I. Withinassay coefficients of variation for $\mathrm{GH}$ were $4.1 \%$ and $4.8 \%$ at $\mathrm{GH}$ concentrations near 10 and $25 \mu \mathrm{g} / \mathrm{l}$, respectively.

\section{Statistical analysis}

Values were expressed as medians and ranges. The GH responses to GHRH, GHRH plus Pyr and GHRH plus $\mathrm{Pz}$ were evaluated as the ratio between peak and baseline (P/B).

Analysis of the results was performed by the following tests: reproducibility of the GHRH test was evaluated by the Pearson correlation, comparison of $\mathrm{P} / \mathrm{B}$ ratios by the Wilcoxon rank test, comparison of results obtained among various subgroups of patients by the MannWhitney or Fisher test (for numerical and dichotomic results, respectively) and correlations by the Spearman test, as appropriate. Owing to wide variations, the comparison between $\mathrm{P} / \mathrm{B}$ ratios after each test was repeated also after $\log$ transformation of raw data; $p<0.05$ was considered to be statistically significant.

\section{Results}

No significant differences among basal GH levels were observed before GHRH administrations or during saline infusion (data not shown).

Growth hormone-releasing hormone elicited a significant increase in $\mathrm{GH}$ levels as compared to baseline values (basal $21.8 \mu \mathrm{g} / \mathrm{l}$, range 6-220; peak $48 \mu \mathrm{g} / \mathrm{l}$, range $8.3-634 ; p<0.00001)$. An analytical evaluation of the individual responses to GHRH showed a wide intersubject variability, ranging from 1.1 to 26.1 (expressed as $\mathrm{P} / \mathrm{B}$ ).

On the contrary, a highly significant correlation was observed between $\mathrm{P} / \mathrm{B} \mathrm{GH}$ response in the 15 patients administered GHRH on two separate occasions ( $r=0.99, p<0.001$ ) (Fig. 1). Basal GH levels were no different between the two tests. These data were utilized for evaluation of pharmacological manipulation of

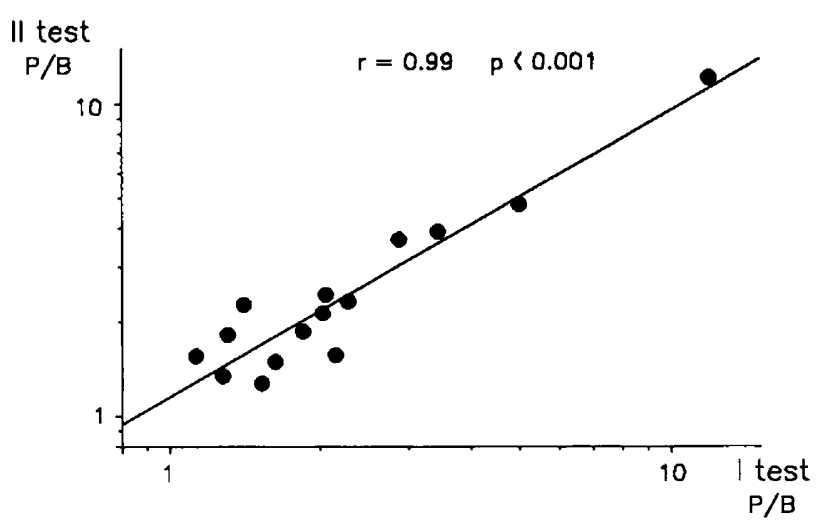

Fig. 1. Reproducibility of GHRH test, expressed as peak/basal (P/B) ratio, in 15 patients.

cholinergic pathways. After transforming the results of the second GHRH test into a ratio of the first, the mean and standard deviation of this ratio were calculated; the SD was 0.22 for the ratio of $\mathrm{P} / \mathrm{B}$ GH levels.

Pretreatment with Pyr did not change basal GH levels but significantly increased the GH response to GHRH (P/ $B=2$, range $1.1-26.1$ for $G H R H$ alone and $P / B=2.6$, range 1.3-34.8 for GHRH plus Pyr; $p=0.0045$ ). In 9 out of 30 patients (cases 1, 4, 7-10, 16, 19, 20), analytical evaluation of these data showed a potentiation of GH response to GHRH after the Pyr pretreatment greater than $2 \mathrm{sD}$ (i.e. greater than 0.44 ) when compared to the response to GHRH alone, whereas the opposite phenomenon was observed in only one patient (case 21) (Fig. 2). No significant difference was observed in responsiveness to Pyr pretreatment among

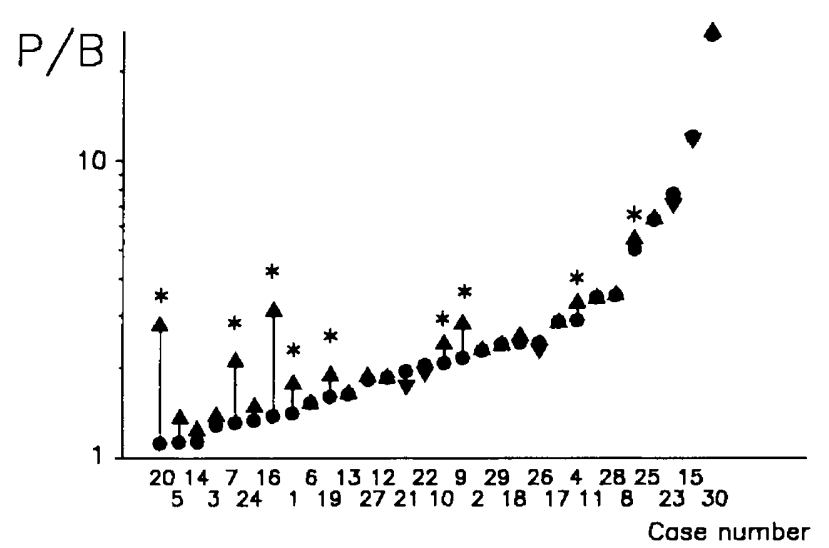

Fig. 2. Individual data of $\mathrm{GH}$ expressed as peak/basal (P/B) ratio in 30 patients (log scale). Each line is for a single patient, whose case number is reported in the lower part of the figure. Data are ranked in increasing order according to $\mathrm{GH}$ response to GHRH alone (filled circles). Arrows show variations in GHRH-induced $\mathrm{P} / \mathrm{B}$ ratios after pyridostigmine pretreatment. Asterisks indicate patients in whom this variation had increased greater than 2 SD when compared to GHRH administration alone. 


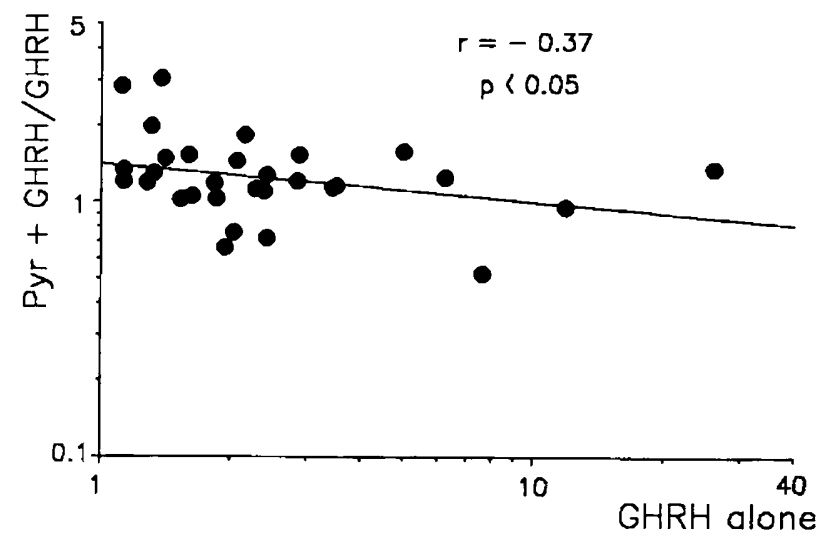

Fig. 3. Inverse correlation between $\mathrm{GH}$ response to GHRH alone (expressed as peak/basal $(\mathrm{P} / \mathrm{B})$ ratio on horizontal axis) and potentiation of GHRH-induced $\mathrm{GH}$ response after pyridostigmine (Pyr) pretreatment (expressed as ratio between P/B after GHRH plus Pyr and after GHRH alone on vertical axis).

patients treated previously or not by neurosurgery and/ or radiotherapy, or among patients whose $\mathrm{GH}$ levels were responsive or not to acute TRH, bromocriptine or octreotide administration. No significant difference was observed in GH response to GHRH after Pyr pretreatment if patients were divided according to sex.

A statistically significant inverse correlation $(r=-0.37, p<0.05)$ was observed between GHRHinduced $\mathrm{GH}$ response (evaluated as $\mathrm{P} / \mathrm{B}$ ) and the potentiation of this response by $\mathrm{Pyr}$ pretreatment (evaluated as ratio between $\mathrm{P} / \mathrm{B}$ after Pyr plus $\mathrm{GHRH}$ and $\mathrm{P} / \mathrm{B}$ after GHRH alone) (Fig. 3).

No correlation was found between age and $\mathrm{GH}$ response to GHRH or Pyr potentiation of GHRHinduced GH response.

No significant change was observed in GHRHinduced $\mathrm{GH}$ response after pretreatment with $\mathrm{Pz}$ in 12 patients $(\mathrm{P} / \mathrm{B}=1.9$, range $1.1-5$ and $\mathrm{P} / \mathrm{B}=2$, range 1.3-6 without and after $\mathrm{Pz}$ pretreatment, respectively). The analytical evaluation of these data showed that in no patient did $\mathrm{Pz}$ pretreatment cause inhibition of $\mathrm{GH}$ response to GHRH, whereas in two patients (cases 1 and 7) an increase was observed.

No significant variation was observed in PRL and TSH levels after each test (data not shown).

No major side effect was observed in any patient during the tests.

\section{Discussion}

A wide intersubject variability in the $\mathrm{GH}$-releasing effect of GHRH was observed among our patients, as in previous studies $(2,3)$. It is to be noted that this response is quite reproducible in the single acromegalic subjects of this series, as shown by the highly significant correlation between the $\mathrm{P} / \mathrm{B}$ GH response in patients administered GHRH on two separate occasions. This is in contrast with normal subjects, in whom a wide intrasubject variability of GHRH-induced GH response also has been shown and attributed to variations of endogenous SRIH secretion (1). Thus, the first conclusion that could be drawn from our data is that SRIH levels do not seem to fluctuate in acromegalic subjects. However, both high and low levels of SRIH might account for the reproducibility of the GHRH test in acromegaly. The results obtained by pharmacological manipulation of cholinergic pathways allowed us to gain further insight into this topic.

In normal subjects, Pyr increases the GH response to GHRH (9). On the basis of indirect animal studies it is widely accepted that the stimulation of $\mathrm{GH}$ secretion by the cholinergic system is mediated by an inhibition of hypothalamic somatostatin release (7), even though Magnan et al. (10) showed direct GHRH stimulation by the cholinergic agonist neostigmine in sheep. Our data are in contrast to Arvat et al. (11), who did not observe any effect of Pyr pretreatment on GHRH-induced GH release in acromegalic patients. If an arbitrary cut-off of $2 \mathrm{sD}$ of within-subject GHRH variability is considered, Pyr potentiation of GHRH-induced $\mathrm{GH}$ response occurred in nine out of 30 patients from this series. A certain degree of hypothalamic SRIH secretion under inhibitory cholinergic control thus may persist in acromegaly. The wide intersubject variability of GHRH-induced $\mathrm{GH}$ response in acromegaly might, in consequence, be related to the degree of hypothalamic SRIH secretion. Alternatively, we may hypothesize in this group of patients about the occurrence of Gsp oncogene mutation that has been reported in nearly $35 \%$ of GH-secreting adenomas, with a poor response to GHRH coupled with a good response to SRIH (12). In our patients the significant inverse correlation observed between the magnitude of the Pyr potentiation of GHRH-induced GH response and the GH responsiveness to GHRH alone (i.e. the lowest the $\mathrm{GH}$ response to GHRH, the greatest the magnitude of Pyr potentiation) is in agreement with the former suggestion.

No difference between sexes was observed in sensitivity of the GHRH-induced GH response to Pyr potentiation, in contrast with the data reported in normal subjects by Barbarino and colleagues (13). It is worthwhile noting, however, that most females in our series were postmenopausal.

What about the non-responders, which were the majority in our series? They do not appear to be a separate population because there was a continuum from the absolute non-responders up to patients whose potentiation is of great magnitude. As neither tumor size nor duration of disease could account for the different pattern, we can hypothesize in the nonresponder patients a derangement of cholinergic pathways or the predominance of alterations at the cellular level, such as the density of receptors.

The antagonism exerted by $\mathrm{Pz}$ on cholinergic neurotransmission did not inhibit significantly the 
GH-releasing effect of GHRH. These findings are in agreement with a previous study of acromegalic patients by Pietschmann et al. (14), which showed the ineffectiveness of atropine in changing the $\mathrm{GH}$ response after GHRH. On the other hand, our results are in partial conflict with the reduction of GHRH-induced $\mathrm{GH}$ release observed in two out of five acromegalic patients by Massara et al. (9) after Pz pretreatment.

In contrast with data observed in normal subjects (15), the ineffectiveness of $\mathrm{Pz}$ in reducing $\mathrm{GH}$ response to GHRH in our study could be due to the persistence in acromegaly of the physiological reciprocal regulation between GH and IGF-I levels and SRIH secretion. It was, indeed, shown in rats that hypothalamic SRIH secretion increases after IGF-I and GH administration (16). Thus, we may hypothesize that in acromegaly SRIH secretion, when preserved, is already maximally activated by high endogenous $\mathrm{GH}$ and IGF-I levels and therefore it cannot be stimulated further by Pz-induced inhibition of cholinergic tone.

In conclusion, although a derangement of the cholinergic pathways or of the coupling between cholinergic and somatostatinergic pathways cannot be ruled out, our study suggests that in acromegaly SRIH secretion does not fluctuate because it is impaired or maximally stimulated. In the latter case, cholinergic neurotransmission can still inhibit, but not further stimulate, hypothalamic SRIH.

\section{References}

1. Gelato MC, Merriam GR, Vance ML, Goldman JA, Webb C, Evans WS, et al. Effects of growth hormone-releasing factor on growth hormone secretion in acromegaly. J Clin Endocrinol Metab 1985;60:251-7

2. Chiodini PG, Liuzzi A, Dallabonzana D, Oppizzi G, Verde G. Changes in growth hormone $(\mathrm{GH})$ secretion induced by human pancreatic GHRH releasing hormone- 44 in acromegaly: a comparison with thyrotropin-releasing hormone and bromocriptine. J Clin Endocrinol Metab 1985;60:48-52

3. Devesa J, Lima L, Lois N, Fraga C, Lechuga MJ, Arce V, et al. Reasons for the variability in growth hormone $(\mathrm{GH})$ responses to GHRH challenge: the endogenous hypothalamic-somatotroph rhythm (HSR). Clin Endocrinol 1989;30:367-77

4. Patel YC, Krishna R, Reichlin S. Somatostatin in human cerebrospinal fluid. N Engl J Med 1977;296:529-33
5. Kelijman M, Williams TC, Downs TR, Frohman LA. Comparison of the sensitivity of growth hormone secretion to somatostatin in vivo and in vitro in acromegaly. J Clin Endocrinol Metab 1988:67:958-63

6. Cryer PE, Daughaday W. Regulation of GH secretion in acromegaly. J Clin Endocrinol Metab 1969;29:386-93

7. Richardson SB, Hollander SS, D'Eletto RD, Greenleaf PW, Than C. Acetylcholine inhibits the release of somatostatin from rat hypothalamus in vitro. Endocrinology 1980;107:1837-42

8. Delitala G, Frulio T, Pacifico A, Maioli M. Participation of cholinergic muscarinic receptors in glucagon and argininemediated growth hormone secretion in man. J Clin Endocrinol Metab 1982;55:1231-3

9. Massara F, Ghigo E, Demislis K, Tangolo D, Mazza E, Locatelli $\mathrm{V}$, et al. Cholinergic involvement in the growth hormone releasing hormone-induced growth hormone release: studies in normal and acromegalic subjects. Neuroendocrinology $1986 ; 43: 670-5$

10. Magnan E, Cataldi M, Guillaume V, Mazzocchi L, Dutour A, Conte-Devolx B, et al. Neostigmine stimulates growth hormonereleasing hormone release into hypophysial portal blood of conscious sheep. Endocrinology. 1993;132:1247-51

11. Arvat E, Ghigo E, Valetto MR, Nicolosi M, Bellone J, Procopio M, et al. Failure of cholinergic agonists and antagonists to modify the GH response to GHRH in acromegaly. Neuroendocrinol Lett 1990;12:155-63

12. Spada A. Arosio M, Bochicchio D, Bazzoni N, Vallar L, Bassetti M, et al. Clinical, biochemical and morphological correlates in patients bearing growth hormone-secreting pituitary tumors with or without constitutively active adenylyl cyclase. J Clin Endocrinol Metab 1990;71:1421-6

13. Barbarino A, Corsello SM, Tofani A, Sciuto R, Della Casa S, Rota $\mathrm{CA}$, et al. Sexual dimorphism of pyridostigmine potentiation of growth hormone (GH)-releasing hormone induced $\mathrm{GH}$ release in humans. J Clin Endocrinol Metab 1991:73:75-8

14. Pietschmann P, Schernthaner G, Luger A. Effect of cholinergic muscarinic receptor blockade on human growth hormone $(\mathrm{GH})-$ releasing hormone-(1-44)-induced GH secretion in acromegaly and type I diabetes mellitus. J Clin Endocrinol Metab 1986;63:389-93

15. Peters JR, Evans PJ, Page MD, Hall R, Gibbs JT, Dieguez C, et al. Cholinergic muscarinic receptor blockade with pirenzepine abolishes slow wave sleep-related growth hormone release in normal adult males. Clin Endocrinol (Oxf) 1986;25:213-7

16. Berelowitz M, Firestone S, Frohman LA. Effects of growth hormone excess and deficiency on hypothalamic somatostatin content and release and on tissue somatostatin distribution. Endocrinology 1981;109:714-9

Received April 29th, 1994

Accepted August 26th, 1994 